\title{
Fear of Cigarette Smoke and the Brain Reaction on Nicotine
}

\author{
Branislav R. Tanasic
}

\begin{abstract}
Nicotine addiction is categorized as severe addiction immediately behind heroin. The third place on the list is cocaine addiction, followed by alcohol, etc. Nicotine is a powerful psychoactive substance that disrupts bio-cell processes and changes behavior. It causes dependence on smokers, but tar is a highly potent killing substance. Therefore, in 1965 the US Congress passed a law on mandatory health warning stickers on tobacco packs. Numerous studies have shown that the health warning does not affect the reduction in the number of cigarettes smoked, contrary this warning motivates smokers to light-up a new cigarette. What actually happens in the smoker's heads and why? $s$ the health warning a subtly designed subliminal message, or is its opposite effect a consequence of the brain filtration mechanism, or is it simply a synergy of the above mentioned phenomena?
\end{abstract}

Keywords - nicotine, smoke, tobacco, warning label.

\section{Introduction}

The tobacco epidemic is one of the biggest public health threats the world has ever faced, killing more than 8 million people a year as the result of direct tobacco use, while around 1.2 million are the result of non-smokers being exposed to second-hand smoke. In some countries, poor children are frequently employed in tobacco farming and they are especially vulnerable to "green tobacco sickness", which is caused by the nicotine that is absorbed through the skin from the handling of wet tobacco leaves. [1]

The general knowledge about the harmful effect of cigarette smoking on health and General Surgeon's report motivated the US Congress that in 1965 adopted the Cigarette Labeling and Advertising Act. The law obliges processors to put a health warning label on the packaging of cigarettes and tobacco products intended for sale in the United States. On the label is printed clearly visible text: Caution: cigarette smoking may be hazardous to your health. President Lyndon B. Johnson signed the bill into law without comment on July 27, 1965. The Federal Trade Commission conducting extensive research, and submit a report to US Congress which says that there is no evidence on the impact of health warnings on reducing the number of smokers, two years after only, the mandatory labeling of tobacco packaging. [2] Why does the direct warning message have the opposite effect, and why such a clear and unambiguous warning text has no effect on reducing the number of smokers?

Published on December 2, 2019.

Branislav R. Tanasic, University of the People Sabac, Serbia and Faculty of Management - FAM, Sremski Karlovci, Serbia. (e-mail: tanasicbrana@yahoo.com)

\section{Materials and Methods}

The experiment was performed in the stable environment with controlled temperature and illumination, respectively all experimental condition was in accordance with Guidelines for the recording and quantitative analysis electroencephalographic activity research contexts. [3]

EEG signals were recording using an MITSAR 201 system, through active Dry electrodes, TDE-200, Florida Research Instruments. The electrode placement system we used was a 10/20 system. The frontal electrode is placed $10 \%$ of the total length above the nasion, and the rest of the electrodes are spaced $20 \%$ between them. We used a referential montage, Fp1, Fp2, F7, F3, Fz, F4, F8, T3, C3, $\mathrm{Cz}, \mathrm{C} 4, \mathrm{~T} 4, \mathrm{~T} 5, \mathrm{P} 3, \mathrm{Pz}, \mathrm{P} 4, \mathrm{~T} 6, \mathrm{O} 1, \mathrm{O} 2$, with a common reference on the ear (A1 \& A2). Impedance is lower than 5 $\mathrm{kOhm}$. Processing and visualization of signals made by using computer software Win EEG. All subjects were given instructions and were asked to abstain from tobacco smoke, at least, four hours before EEG monitoring. All participants were warned that must no have neurological disorders and must no be taking mind altering medications or some illegal substances. The ending, all of them were required to sign the consent form. Participants in the experiment were exposed to a stimulus, a series of photographs that have provoked a certain mental and emotional states. After displaying each photo a $5 \mathrm{sec}$ long baseline recorded. After presented a picture, marked times of this activity. Computer broadcasting photo stimuli synchronized with a computer EEG device, so that any change in the stimulus automatically records. Upon completion of the EEG, monitoring subjects were asked to complete a questionnaire. The questionnaire consisted of closed answers, (Likert scale 1 to 5), about average daily cigarette smoking, then fear of the consequences of smoking, reducing the number of cigarettes due to the effects of health warning labels, etc.

\section{EEG Scanning and Results}

Neuromarketing research encompassed a total of 50 participants, of which 30 were male and 20 were female, all right-handed, different occupations and level of education. All participants selected as right-handed because of differences that occur in brain lateralization. Through neurophysiological research conducted using EEG, research raw data need to be processed prior to the analysiscorrection of EEG artifacts. The signals usually acquired during EEG is generally contaminated with different noise sources, power line interference $50 \mathrm{~Hz}$, and severe biological signals. Win EEG offers a methods of digital EEG filtering, the list a set of parameters we used: speed $30 \mathrm{~mm} / \mathrm{sec}$, gain /absolute peak-to-peak threshold/ 200 milliV, low cut 0.1 sec $(1.6 \mathrm{~Hz})$, high cut $30 \mathrm{~Hz}$, and notch filter to suppress AC line, $45-55 \mathrm{~Hz}$, (Europian AC frequency standard is $50 \mathrm{~Hz}$ ). 
Eye blink artifacts separation performed using an Independent Component Analysis (ICA) methods. Throughout basic statistical analyzes, EEG findings, and discussion will present data and evidence to suggest the true nature of the warning labels and its actual effect on smokers.

In this review, only some aspects of the conducted research related to smoking fear and the impact of the health warning sticker are analyzed. The research as a whole can be seen in [4]. The first step is to compute the correlation between several important issues of this research. Pearson correlations between questions: Are you afraid of the consequences of smoking and cigarette packing warning label influence, (Table 1), shows a significant degree of impact warning labels on cigarette smokers, Sig (2-tailed) is 0.000 . The size of correlation of 0.732 means a strong positive linear relationship. [5]

\section{Afraid of consequences / Warning label influence}

\begin{tabular}{|c|c|c|}
\hline Pearson Coreleations & 1 & .732 \\
\hline Sig. 2 tailed & & .000 \\
\hline $\mathrm{N}$ & 50 & \\
\hline $\begin{array}{l}\text { Are you afraid of the } \\
\text { consequences of smoking }\end{array}$ & & \\
\hline Pearson Coreleations & .732 & 1 \\
\hline Sig. 2 tailed & .000 & \\
\hline $\begin{array}{l}\text { Warning cigarette } \\
\text { packing label influence }\end{array}$ & & \\
\hline $\mathrm{N}$ & 50 & \\
\hline
\end{tabular}

When Pearson's correlation coefficient to recalculate in the coefficient of determination could see how much of the variance of two variables together 53,5\%. What are actually means; that more than $53 \%$ responders have a fear of the consequences of smoking, which is caused by label warnings. By designing this study, in accordance with the text of the warning labels, we started from the set hypotheses: The label of health warnings on packets of cigarettes really have the effect on smokers by reducing the desire to smoke, so smokers reduce the number of cigarettes smoked. Preliminary results showed that the respondents gave oral answers in the expected framework, adapted to social norms and socially acceptable standards, which is actually the main problem of the classic survey. Now the question again: Are you afraid of the consequences of smoking? the answer to a question, but under EEG monitoring shows the following results.

\section{Average response to a question about the fear of the consequences of smoking.}

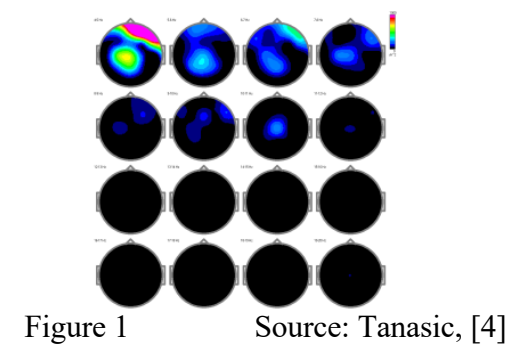

Figure 1 shows the average respondent's answer. Lack of fear in response to stimulus as a warning on the package despite the fact that this horrific photos of deadly diseases.
This controversial attitude towards health warning is further proof that there is often a significant difference between the responses to the questionnaire, and what is really happening in the brain of respondents, judging by the fact that the majority of respondents stated that they fear the health warnings, and they therefore significantly reduce the number of cigarettes smoked.It is said that the $53.5 \%$ of respondents expressed fear of the consequences of smoking, but the majority of respondents smoked one, or more than one pack of cigarettes a day!

Obviously, the message of a warning or a terrible pictures of diseased organs does not reach passionate smokers and they continue with the same enthusiasm to enjoy the smoke of cigarettes.

\subsection{Is the Health Warning Label Subliminal Message?}

There are stimuli that are of very low intensity or occur very quickly, so they are below the limit of conscious observation. Such stimuli are called subliminal stimuli. Very weak signals, stimuli below the threshold of conscious perception are not registered consciously. The message is concealed, transformed, and communicates with consumers with associative connections at the subconscious level. Subconscious communication is often far more effective than direct addressing, provoking, and causing the desired effect, sometimes completely contrary to what the content posted seems to indicate. The health warning sticker is a subtle message; at first glance it warning smokers of at risk of consuming tobacco products, but at the same time produces the opposite effect in smokers. By its form, the sticker is the informative warning message, but in its effect, the sticker is a subtle subliminal message. Neuromarketing is flawless proved that the label does not discourage smokers from tobacco but strongly stimulates the desire to light up a new cigarette. All the above leads to the conclusion that the etiquette is actually hidden message where smokers can not resist, and this is a feature of a firstclass subliminal message. Small warning label ended a great job [4].

\subsection{Brain Filtration Helps to Neglect the Warning?}

In the real three-dimensional environment, in the human brain there is only information recorded by the senses. All sensory pathways, apart from one fragment of scent's nerves, lead to cortex across the thalamus, integrate, and then passed on to the cortex sensory centers. This communication is a constant two-way exchange of information; the cortex sends a signal back to the thalamic reticular nucleus-TRN. Depending on the quality and interest for the particular content, his thalamic structure can activate the neurotransmitter GABA, to regulate thalamocortical communication, through modulating the received information by increasing the essential signals, while less important information decreases or completely extinguishes. On this way, the thalamus selects the information create the possibility to the individual to fully concentrate on the object of attention, the neurological process of filtering known as sensory gating. [6] Psychologist Donald Broadbent, in their work Perception and Communication, established and developed a concept of the selective brain process. [7] Often, in the literature, an example of a cocktail party is encountered in the explanation of this 
phenomenon. Du Plessis in his book The Advertised Mind, explains the details of how to focus on what one person says when many people speaking simultaneously, the cocktail party effect. The room is full of noisy people; everyone is talking about the same volume. While you are barely following the interlocutor, someone in a nearby mentions your name, and "You involuntarily switch your attention to the person who mentioned your name, and listen to a few words of that conversation. You realize the participants are not talking about you, but about some else with the same first name, and switch your attention back to your companion." [8]

How the human brain reacts like an inborn Adblocker? When the cortex receives a type of information which considers it a priority, it sends a signal back to a part of the thalamus known as the thalamic reticular nucleusTRN. Located between thalamus and cortex is a thin lamina of neurons, which may function as an attentional gate. [9] TRN uses the neurotransmitter GABA, to regulate thalamocortical communication, and inhibit transmission of other less interesting signals from the thalamus to the cortex. In cooperation with the associative cortex, (over the thalamocortical-thalamic loop), the thalamus can modulate the received information by increasing the essential signals. Therefore, it should be kept in mind that only the contents that are the subject of attention can be memorized, so that the contents that were discarded by the filtration process, for the conscious brain component, did not actually occur. A study was conducted on mice with and without the ErbB4 gene to determine their impact of them for attention. ErbB4 normally decreases the influence that the cortex has over the reticular nucleus, so without ErbB4 cortical feedback to the reticular thalamic nucleus is stronger, and thus there is greater suppression of irrelevant data. [10] It is extremely important to understand that ErbB4 plays a very important role, crucial for intellectual and cognitive function.

The cortical-thalamic-cortical loop characterized the health warning message as an unwanted throughout the filtering process, neglect or even rejects the contents of a label, and its effect is reduced to triggering a desire for a new quantity of nicotine. The smoker lights up a new cigarette and begins to enjoy into nicotine effects again, and what is happening then?

\subsection{Nicotine in the Brain}

The bloodstream transports nicotine to the brain for about 7 to 10 seconds after the first smoke of cigarettes. Since nicotine has an almost identical molecular structure such as acetylcholine, thanks to this feature it is compatible with receptors designed to bind acetylcholine, so this mimicry allows it to take its place on the receptors.In this way, interrupts the transmission of information that an acetylcholine would transfer as a neurotransmitter. The adverse effect of nicotine on the brain is reflected through its increased concentration in relation to acetylcholine, so it overactive stimuli of the receptor cell, which makes them less susceptible. Since target neurons are accustomed to these artificially elevated levels of chemistry, habit is gradually developing so that neurons can not normally function with the usual dose of acetylcholine. That is why there is a need for abnormal levels of nicotine induced stimulation. This is the chemical basis of dependence. It is important to understand that while acetylcholine acts on several types of receptors and thus achieves a balance of activity, nicotine acts only on one receptor type that causes unilateral effects, increases blood pressure, the heart accelerates the rhythm. [11] Another dangerous mechanism for the action of nicotine is demonstrated by the simultaneous destruction of the enzyme mono-amineoxidase $\mathrm{B}$, which is responsible for the degradation of dopamine. Due to the lack of this ferment, dopamine accumulates excessively resulting that the smokers having a sense of satisfaction, and therefore happy and hurry lighting-up a new cigarette. The false or genuine impression of enjoying smoking, consumers of tobacco is in the nicotine trap and is getting harder to escape from it.

\section{Conclusion}

How much nicotine dependence is distracting the cigarette smokers to see and understand a clear message of health warning on tobacco packs? Does the critical impact have a specifically designed warning message text or the need for nicotine is so strong that the warning is completely ignored? By its form, the health warning sticker is the informative message, but in its effect seems that the sticker is a subtle subliminal message. Neuromarketing is flawless proved that the label does not discourage smokers from tobacco but instead that this message strongly stimulates the desire to light up a new cigarette. In cooperation with the present need for the brain for additional amounts of nicotine smokers caught in a dangerous network of addiction, the warning is ignored.

It's known that millions of cigarette smokers die every year, while around 1.2 million are the result of nonsmokers being exposed to second-hand smoke, (estimated about 65000 children die each year from illnesses attributable to second-hand smoke). There is a dramatically high percentage of smokers in the underdeveloped countries, and most of it is from the poorest layers of society. It's terrifying WHO data that these people spend couple of times more money on tobacco than on food, medicine or education. In fact, education is crucial. It has been proven that more educated people significantly less use tobacco products. Only through education can people be informed and understand all aspects of the harms caused by smoking cigarettes either as active smokers or as innocent passive smoke inhalers. On the other hand, the subconscious effect of a well-designed message of health warning, assisted by various chemicals into tobacco products that increase addiction, is a difficult opponent to most anti-smoking campaigns.

\section{References:}

[1] World Health Organization, Tobacco, WHO, 29 May 2019 [online] https://www.who.int/news-room/fact-sheets/detail/tobacco

[2] Federal Trade Commision, Report to Congress, Persuant to the Federal Cigarette Labeleing and Advertising Act, F T C, 1967

[3] Pivik R. T., R. J. Broughton, R. Coppola, R. J. Davidson, N. Fox \& M. R. Nuwer, Guidelines for the recording and quantitative analysis electroencephalographic activity research contexts, USA, Psychophysiology,30 (1993), Cambridge University Press

[4] Tanasic R. Branislav, What is actually the warning label on thepackage of cigarettes? 2018. International Journal of Contemporary Research and Review, Volume 9, Issue 2, 2018, pgs. 20383-20392 
[5] Cohen J. W. Statistical power analysis for the behavioral sciences, $2^{\text {nd }}$ ed. Hilsdale, NY: Lawrence Erlbaum Associates, 1998.

[6] Banich T. Marie, Cognitive neuroscience and neuropsychology ${ }^{(2 \mathrm{nd}}$ Edition) Boston, Houghton Mifflin Company, 2004, pgs. 49-50

[7] Broadbent E. Donald, Perception and Communication, Oxford, Pergamon press, 1958,

[8] Du Plessis Erik, The Advertised Mind, the ground-breaking insights into how our brains respond to advertising, London, Millward Brown, 2005.

[9] McAlonan Kerry, Verity J. Brown, \& Eric M. Bowman,Thalamic Reticular Nucleus Activation Reflects Attentional Gating During Classical Conditioning, The Journal of Neuroscience, 2000. 20(23): 8897-890.

[10] Lewis Jordan Gaines, This Is How the Brain Filters Out Unimportant Details, [online]. https://www.psychologytoday.com/gb/blog/brainbabble/201502/ishow-the-brain-filters- outunimportant-details

[11] Greenfield Susan, The Human Brain - A Guided Tour, London, Phoenix Ltd 1998.

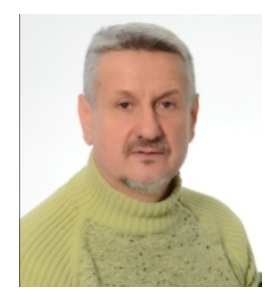

A narrow field of interest is subliminal and neuromarketing. Have own EEG device /electroencephalography/ organize researches aimed at developing the ability to better visualize and understanding consumer subconscious responses. Besides the work of impact of sensory branding on the decision-making process, recently finished the research of impact the health warning label on the cigarette on smokers. Currently in the preparation to doing the research of the significance of the binaural arousal on the brain bilateral synchronization. Recently published a book, Neuromarketing - A Mirror of the Consumers, issued by Tablo Publishing, Melbourn. Editorial board member of several neuromarketing journals and similar fields.

Long-time professor currently employed at National University, and at Faculty of Management, Sremski Karlovci (FAM) as a professor of Management, Human Resource Management, Business Communication, Marketing. 